\title{
TRANSPARÊNCIA NA FUNÇÃO PÚBLICA: PERSPECTIVAS DO DEVER DE INFORMAÇÃO
}

\author{
Carlos José de CARVALHO NETO ${ }^{1}$ \\ Luiz Antônio Campos DINIZ
}

\author{
${ }^{1}$ Graduado em Direito pela FADIVA, Pós-graduado em Direito Processual Civil pela PUC-MG, e-mail: \\ carloscjneto@yahoo.com.br \\ ${ }^{2}$ Bacharel em Direito, dinizlac@gmail.com.
}

Recebido em: 09/09/2015 - Aprovado em: 21/06/2016 - Disponibilizado em: 30/07/2016

\begin{abstract}
Resumo: Este artigo tem o objetivo de evidenciar a obrigatoriedade e a abrangência dos princípios da publicidade e da transparência na administração pública brasileira, com enfoque na divulgação das contas públicas como forma de se proporcionar o seu conhecimento pela sociedade em geral, munindo-a das informações essências ao controle externo da administração. A pesquisa foi realizada através de revisão bibliográfica visando formar a base conceitual e legal para o desenvolvimento do trabalho, com a exposição da evolução legislativa, sobretudo infraconstitucional, que visa a efetivação do princípio da publicidade. A pesquisa revela a importância da Transparência da Função Pública, onde nos mostra que através dela poderá haver vastos benefícios para o Brasil, propiciando uma relação mais saudável e transparente entre a sociedade e o Governo, com vista a uma melhor fiscalização da coisa pública e, consequentemente, a redução da corrupção que por vezes se vale da obscuridade fruto da sombra opaca da ausência de transparência no trato com a res publica.
\end{abstract}

Palavras-chave: Gestão pública. Publicidade. Transparência. Sociedade.

\begin{abstract}
This article aims to highlight the requirement and scope of the principles of publicity and transparency in the Brazilian public administration, focusing on the dissemination of public accounts as a way to provide their knowledge society as a whole, providing them the information essences to external control of the administration. The survey was conducted through literature review in order to form a conceptual and legal basis for development work, with the exhibition of the legislative developments, especially infra, aimed at the realization of the principle of publicity. The survey reveals the importance of Transparency of Public Service, which shows us that through it could bring vast benefits to Brazil, providing a healthier and more transparent relationship between society and government, as well as better monitoring of public affairs and consequently reducing corruption, which sometimes worth of fruit dark opaque shadow of the lack of transparency in dealing with the res publica.
\end{abstract}

Keywords: Public management. Advertising. Transparency. Society.

\section{INTRODUÇÃO}

Neste artigo, por meio da abordagem da evolução da legislação, buscamos demonstrar que o direito à informação é um dos instrumentos de inibição de desvios na conduta do administrador publico, além de fomentar o controle social com vista à redução da corrupção na gestão pública. Pautamos pela importância da transparência como meio de munir com informações a sociedade e instiga-la a exercer o controle social da atividade publica, visando a observância, por parte do gestor publico, dos 
princípios constitucionais norteadores da administração pública.

De acordo com a Constituição Federal, as entidades que compõem a estrutura da administração pública brasileira são obrigadas a prestar contas do uso de recursos públicos e a respeitar, entre outros princípios da administração pública, o princípio da publicidade.

Podemos destacar que a publicidade é o princípio constitucional que permite ao cidadão e aos órgãos de controle fiscalizar os atos de gestão pública. Para que esses atos sejam válidos, é necessário que haja, oficialmente, a publicação conferindo-lhes o início de seus efeitos jurídicos e para efetivar a transparência, permitindo o seu conhecimento e controle pela sociedade e demais órgãos competentes. Mais do que garantir o atendimento da legislação, as iniciativas de transparência na função pública constituem uma política de gestão favorável ao exercício da cidadania pelos componentes de uma determinada sociedade.

Celso Antônio, comentando sobre o principio constitucional da publicidade nos lega:

Consagra-se nisto o dever administrativo de manter plena transparência em seus comportamentos. Não pode haver em um Estado Democrático de Direito, no qual o poder reside no povo $[\ldots]$, ocultamento aos administrados dos assuntos que a todos interessam, e muito menos em relação aos sujeitos individualmente afetados por alguma media (MELLO, 2015, p. 117).

Esse dever de transparência e de informação incide sobre a administração, ou seja, sobre a administração pública como um todo, sendo necessário, num primeiro plano, entender o conceito de administração pública.

\section{ADMINISTRAÇÃO PÚBLICA:}

\section{Conceitos básicos}

Existem várias discussões acerca do conceito de Administração Pública. Nota-se que há uma confusão de conceitos entre Governo e Administração Pública, que embora geralmente andem juntos, possuem objetivos diferentes.

Segundo Meireles (1993), a Administração é o conjunto de funções necessárias para a prestação eficiente dos serviços públicos, é o desempenho longo e organizado, legal e técnico dos serviços relativos ao Estado, ou assumidos por ele em prol da coletividade, visando o cumprimento do princípio da supremacia do interesse público; enquanto Governo é o conjunto de poderes e órgãos responsáveis pelas funções estatais básicas. 
Meirelles (2000) afirma ainda que “[...] administração pública é todo o aparelhamento do Estado, preordenado à realização de seus serviços, visando à satisfação das necessidades coletivas".

Assim, governo seria o Estado em si, e a administração, a forma de gerir o Estado, a fim de que a coisa e o interesse público sejam bem geridos e possam proporcionar satisfação à sociedade quanto ao resultado esperado da sua atuação precípua ou mesmo secundária.

Di Pietro (2006) afirma que, em sentido objetivo, "a Administração Pública pode ser definida como a atividade concreta e imediata que o Estado desenvolve, sob regime jurídico de direito público, para consecução dos interesses coletivos". Subjetivamente, ela define a Administração Pública como “conjunto de órgãos e de pessoas jurídicas aos quais a lei atribui o exercício da função administrativa do Estado".

Slomski (2003) considera serviço público como conjunto de atividades-meio e de atividades-fins exercidas ou colocadas à disposição, prestadas diretamente, permitidas ou concedidas pelo Estado, visando proporcionar o maior grau possível de bemestar social da coletividade.

Em todos os conceitos fica clara a relação entre a Administração Pública e o Governo, sempre deixando evidente que o objetivo de ambos é satisfação do melhor “interesse publico, mediante o uso dos poderes instrumentalmente necessários conferidos pela ordem jurídica" (MELLO, 2015, p. 29).

Desta forma, em qualquer dimensão que se possam entender as expressões Governo e Administração, o certo é que em nenhuma delas a aplicação invariável dos princípios gerais do direito público pode ser afastada, incluído-se o dever de publicidade dos atos do poder público, como forma de viabilizar o controle destes atos viabilizado pelo seu conhecimento.

\section{CONTROLE SOCIAL}

O controle social é a participação do cidadão na gestão pública, na fiscalização, no monitoramento e no controle das ações da Administração Pública. Trata-se de importante mecanismo de fortalecimento da cidadania que contribui para aproximar a sociedade do Estado, abrindo a oportunidade para a sociedade acompanhar as ações dos governos e cobrar uma boa gestão pública.

Uma administração pública, que se pretende transparente quanto aos seus atos, deve facilitar aos cidadãos 0 acesso às informações de interesse público numa linguagem clara e de fácil entendimento.

A Constituição Federal, no seu artigo 37, ao estabelecer o princípio da publicidade, tem por escopo manter a total transparência 
dos atos da Administração Pública, que não poderá ocultar ao administrado o conhecimento dos assuntos que lhe interessam direta ou indiretamente.

Além disso, o controle social forte e atuante auxilia na prevenção da corrupção, pois quando a sociedade está atenta à atuação dos gestores e fiscaliza a aplicação do dinheiro público, as chances de ocorrerem desvios e irregularidades tendem a diminuir.

O aumento do controle pela sociedade e da responsabilização dos gestores públicos e a constante busca na transparência dos atos e das contas públicas, são fatores imperativos para a manutenção da democracia e fomentar o constante movimento de combate à corrupção no setor público.

A partir da Constituição, uma nova legislação participativa foi implementada, criando mecanismos de participação e controle social, como os conselhos de políticas públicas, conferências, mesas de diálogo, fóruns de debate, audiências públicas, ouvidorias, orçamentos participativos, dentre outros.

Esses mecanismos de participação e controle social são importantes instrumentos da sociedade na fiscalização, controle e avaliação da gestão pública, pois é com a vigilância e o monitoramento das ações do Estado que os cidadãos podem orientar e redirecionar as atividades do poder público, não apenas no campo do combate à corrupção, mas em relação ao atendimento do interesse público de modo geral.

É certo que o êxito da atuação da sociedade na vigilância do Estado depende de diversos fatores, como o acesso a informações públicas; o conhecimento técnico para realizar a análise de dados e produzir informações; condições de disseminar ideias, críticas e reivindicações e, claro, a capacidade de mobilizar outras pessoas e entidades em torno delas.

Neste passo, a legislação tem evoluído na busca da efetivação do princípio constitucional da publicidade.

\section{FUNDAMENTAÇÃO LEGAL}

O incessante investimento na efetivação da transparência na Administração Pública é tido como condição imperiosa para que o Brasil continue progredindo no processo de desenvolvimento econômico, social e na consolidação da democracia. Nesse contexto, a transparência se torna materializada por meio do acesso pelo cidadão às informações governamentais, tornando mais democrática a relação entre Estado e sociedade civil.

Em princípio, todo ato administrativo deve ser publicado, porque pública é a administração que o 
realiza, só se admitindo sigilo nos casos de segurança nacional, investigações policiais ou interesse superior da administração a ser preservado em processo previamente declarado e sigiloso. (NOGUEIRA, 2006, p.30)

$\mathrm{Na}$ busca da eficiência na satisfação do interesse público, se faz necessário que o Estado atue, constantemente, no combate à corrupção entranhada na administração pública. Trata-se de um processo de mudança cultural da sociedade a reverberar nas suas instituições e nas pessoas que nelas atuam, e passa pela implantação de modelos éticos na gestão da coisa pública. Portanto, a edições de Leis é apenas um passo no combate a este complexo jeito de agir chamado corrupção.

A Constituição Federal estabelece que a pessoa física ou jurídica, pública ou privada, que utilize, arrecade, guarde, gerencie ou administre dinheiros, bens e valores públicos tem o dever de prestar contas e dar publicidade aos seus atos.

No Brasil, o acesso à informação pública está inscrito no capítulo I da Constituição - dos Direitos e Deveres Individuais e Coletivos - particularmente no inciso XXXIII do art. $5^{\circ}$.

Todos têm direito a receber dos órgãos públicos informações de seu interesse particular, ou de interesse coletivo ou geral, que serão prestadas no prazo da lei, sob pena de responsabilidade, ressalvadas aquelas cujo sigilo seja imprescindível à segurança da sociedade e do Estado. (CF, 1988)

É importante destacar o que está no $\S$ $2^{\circ}$ do art. 216 da Constituição Federal: “Cabem à administração pública, na forma da lei, a gestão da documentação governamental e as providências para franquear sua consulta a quantos dela necessitem".

Conforme as organizações públicas ampliam o volume das operações orçamentárias, financeiras e patrimoniais, precisam implantar novas tecnologias de informação visando a transparência de seus atos.

Tal necessidade ocorre, também, porque o cidadão está cada vez mais exigente por resultados, ou seja, ele quer mais serviços públicos, mais segurança, mais hospitais, mais obras públicas e, paradoxalmente, pleiteia menos impostos, menos taxas e menos contribuições.

Consequentemente, os administradores precisam estar conscientes de que as organizações

governamentais devem estar capacitadas a transformar os dados disponíveis em informações úteis ao processo decisório, com o objetivo de facilitar a implementação das ações 
de governo. (SILVA, 2002, p. 234).

No âmbito infraconstitucional, a Lei de Responsabilidade Fiscal (Lei complementar 101/2000) representou um marco para a administração pública brasileira, estabelecendo normas de finanças públicas voltadas para a responsabilidade na gestão fiscal, para garantir uma gestão responsável, eficiente, eficaz e, sobretudo, transparente, como forma de assegurar à sociedade $o$ acompanhamento através da divulgação de todos os atos praticados pela administração.

A Lei de Responsabilidade Fiscal tem como base fundamental os princípios do planejamento, da transparência e da participação popular. A participação da sociedade, alicerce do controle social, depende fortemente da transparência das ações dos representantes governamentais e da divulgação das contas públicas, pois sem as devidas informações fica impossível haver o controle dessas ações.

De acordo com o art. 48 da Lei de Responsabilidade Fiscal (LRF):

São instrumentos de transparência da gestão fiscal, aos quais será dada ampla divulgação, inclusive em meios eletrônicos de acesso público: os planos, orçamentos e leis de diretrizes orçamentárias; as prestações de contas e o respectivo parecer prévio; o Relatório Resumido da Execução Orçamentária e o Relatório de Gestão Fiscal; e as versões simplificadas desses documentos (LRF, 2000).

Assim, a Lei de Responsabilidade Fiscal se converteu no mais importante código de conduta para os gestores públicos, pois seu conteúdo estabelece normas rigorosas para que os governantes ajam com responsabilidade na gestão dos recursos federais, estaduais e municipais.

Ficou evidente que a referida lei garantiu aos cidadãos brasileiros o acesso às contas públicas, permitindo que fiscalizem a ação planejada e transparente, na qual os riscos são prevenidos e os desvios corrigidos.

Para reforçar a transparência da gestão fiscal, editou-se, posteriormente, a Lei Complementar $\mathrm{n}^{\circ}$ 131, de 27 de maio de 2009, acrescentando dispositivos à Lei de Responsabilidade Fiscal, estabelecendo-se a determinação de disponibilização, em tempo real $^{1}$, de informações pormenorizadas sobre a execução orçamentária e financeira da União,

\footnotetext{
${ }^{1}$ Tempo real: a disponibilização das informações, em meio eletrônico que possibilite amplo acesso público, até o primeiro dia útil subsequente à data do registro contábil no respectivo SISTEMA, sem prejuízo do desempenho e da preservação das rotinas de segurança operacional necessários ao seu pleno funcionamento; (Inciso II, $\S 2^{\circ}$ do Decreto 7.185, de 27 de maio de 2010).
} 
dos Estados, do Distrito Federal e dos Municípios.

Leciona Bicalho sobre a Lei Complementar $n^{\circ}$ 131/09:

\begin{abstract}
Além de reafirmar a participação popular no ciclo orçamentário, a Lei diz que todos os gestores públicos do país estão obrigados a disponibilizar na internet ("em meios eletrônicos de acesso publico") informações detalhadas e atualizadas para os cidadãos e cidadãs, sobre a execução orçamentária (receitas e despesas) de todos os órgãos dos poderes Executivo, Judiciário e Legislativo da União, Estados, municípios e do Distrito Federal. (BICALHO, 2009, p10).
\end{abstract}

Desta forma, todo cidadão pode conhecer os atos da administração pública por meio das melhores tecnologias de informação. A transparência passa, assim, a funcionar como o inibidor eficiente de todo o mau uso do dinheiro público.

A inovação em questão, do ponto de vista prático/jurídico, pretendeu retirar das sombras e da apatia do poder público a decrépita prática de não se dar a devida publicidade à prestação de contas das verbas orçamentárias.

Mesmo com essas legislações que tratam sobre a transparência na gestão pública, ainda se notava um descaso muito grande por parte dos administradores quanto a disponibilização das informações solicitadas pela sociedade. Diante deste quadro, foi sancionada, em novembro de 2011, a Lei ${ }^{\circ}$ 12.527 - Lei de Acesso à Informação garantindo que "qualquer interessado poderá apresentar pedido de acesso a informações aos órgãos e entidades", sendo vedadas "quaisquer exigências relativas aos motivos determinantes da solicitação de informações de interesse público".

A aprovação da Lei de Acesso à Informação vem causando um grande impacto na rotina da Administração Pública, promovendo mudanças tanto culturais quanto procedimentais. É preciso que os agentes públicos compreendam que o Estado é apenas o guardião da informação pública, devendo disponibilizar a sociedade sempre que solicitado, sem perguntar o porquê ou para quê.

Uma administração que se pretende transparentes quanto aos seus atos deve facilitar aos cidadãos o acesso às informações de interesse público numa linguagem clara e de fácil entendimento.

Importante ressaltar que não basta somente divulgar as informações públicas. É preciso que os governos se preocupem também em atender de maneira ágil e tempestiva as solicitações de informações e de documentos que são requisitados pela sociedade. 
Além disso, quando se fala em transparência e acesso à informação, a Lei 12.527/2011 estabelece que os dados devam ser abertos, ou seja, disponibilizados na internet, em formato livre de restrições de direitos autorais e licenças, visando proporcionar maior facilidade na sua obtenção, análise e reutilização pelo cidadão.

Como dito, esta lei estabelece que as entidades públicas são obrigadas a divulgar na internet, em uma linguagem clara e de fácil acesso, informações sobre a administração pública. Deve constar, no mínimo, registro das competências e estrutura organizacional, endereços e telefones das respectivas unidades e horários de atendimento ao público. Também devem ser publicados registros de quaisquer repasses ou transferências de recursos financeiros e informações sobre licitações, inclusive os editais e resultados.

A lei exige, ainda, que fiquem expostos na internet dados gerais para 0 acompanhamento de programas, ações, projetos e obras do governo, além de respostas às perguntas mais frequentes da sociedade. As informações devem ser mantidas sempre atualizadas.

Apenas os municípios com menos de 10 mil habitantes estão desobrigados a apresentar, em um site na internet, os dados sobre as operações municipais, mas, no entanto, os órgãos desses pequenos municípios são obrigados a prestar informações sempre que solicitadas.

A Lei 12.527/2011 representa uma mudança de paradigma em matéria de transparência pública por estabelece que o acesso à informação se tornou regra e que o sigilo passa a ser exceção. Através dela, todo cidadão poderá solicitar as informações da gestão pública.

Todo processo para implementação de um novo paradigma revela dificuldades, com vários desafios a serem enfrentados para se vencer a cultura do sigilo que, de forma silenciosa e invisível, ainda prevalece na gestão pública. Os servidores terão um papel fundamental para a mudança cultural, pois lidam cotidianamente com a informação pública, com a sua produção e com o seu arquivamento, devendo possuir todo o conhecimento normativo necessário para fazer com que as informações sejam efetivamente prestadas e a transparência seja efetivada.

\section{GARANTIA DO CIDADÃO AO ACESSO A INFORMAÇÃO}

Podemos notar claramente que a lei 12.527/2011 é um marco histórico na luta pela consolidação da democracia no nosso país e também pelo fortalecimento das ferramentas de combate e controle à corrupção, pois obriga órgãos públicos 
federais, estaduais e municipais (ministérios, estatais, governos estaduais, prefeituras, empresas públicas, autarquias etc.) a disponibilizarem informações relacionadas às suas atividades a qualquer pessoa que solicitar os dados, conforme disposto no seu artigo $1^{\circ}$.

Portanto a Lei 12.527/2011 efetiva o direito previsto na Constituição de que todos têm a prerrogativa de receber dos órgãos públicos as informações do seu interesse pessoal e, também, aquelas de interesse coletivo. Isto significa que a Administração além de cumprir seu papel na divulgação de suas ações e serviços, deve estar preparada para receber demandas específicas, conforme disposto no seu art. 10:

"Qualquer interessado poderá apresentar pedido de acesso a informações aos órgãos e entidades referidos no art. $1^{\underline{o}}$ desta Lei, por qualquer meio legítimo, devendo o pedido conter a identificação do requerente e a especificação da informação requerida".(LAI, 2011)

Para garantir a eficiência e eficácia da lei, foram estabelecidos prazos para que sejam repassadas as informações ao solicitante. A resposta deve ser dada imediatamente, se estiver disponível, ou em até 20 dias, prorrogáveis por mais 10 dias.
O pedido não precisa ser justificado, apenas conter a identificação do requerente e a especificação da informação solicitada.

O Decreto 7.724 , de 16 de maio de 2012, no seu art. $4^{\circ}$ estabelece que o serviço de busca e fornecimento das informações é gratuito, salvo cópias de documentos: "A busca e o fornecimento da informação são gratuitos ressalvados a cobrança do valor referente ao custo dos serviços e dos materiais utilizados, tais como reprodução de documentos, mídias digitais e postagem”.

Nas situações em que as informações estejam sob algum tipo de sigilo previsto em Lei, o requerente tem o direito de obter o inteiro teor da negativa de acesso.

De acordo com a Lei 12.527/2011, fica estabelecido que os órgãos e as entidades públicas deverão divulgar informações de interesse coletivo, salvo aquelas cuja confidencialidade esteja prevista no texto legal. Isto deverá ser feito através de todos os meios disponíveis e obrigatoriamente em sítios da internet. Porém, para fins dessa lei, os municípios com população até 10.000 (dez mil) habitantes estão dispensados do seu cumprimento, conforme art. $8^{\circ}$ no seu $\S 4^{\circ}$.

Para facilitar o pedido de informação pela sociedade, a lei determina ainda que os órgãos públicos criem centros de atendimento dentro de cada órgão chamados de SICs (Serviços de Informação ao Cidadão). Esses centros deverão contar com estrutura 
suficiente capaz de atender e orientar o público quanto ao acesso a informações de interesse coletivo como, por exemplo, tramitação de documentos, processos de licitações e gastos públicos.

O decreto $\mathrm{n}^{\circ} 7.724$, de 16 de maio de 2012, que Regulamenta a Lei $\mathrm{n}^{\mathrm{o}} 12.527$ estabelece no seu art. $9^{\circ}$ : trata de vários termos relacionados a matéria, tornando-se importante conhecer alguns conceitos que o Decreto ${ }^{\circ} 7.724 / 2012$, no seu Art. $3^{\circ}$ considera:

\author{
Art. 9ำ Os órgãos e \\ entidades deverão criar \\ Serviço de Informações ao \\ Cidadão - SIC, com o \\ objetivo de: \\ $\mathrm{I}$ - atender e orientar o \\ público quanto ao acesso à \\ informação; \\ II - informar sobre a \\ tramitação de documentos \\ nas unidades; e \\ III - receber e registrar \\ pedidos de acesso à \\ informação. \\ Parágrafo único. Compete \\ ao SIC: \\ I - o recebimento do pedido \\ de acesso e, sempre que \\ possível, o fornecimento \\ imediato da informação; \\ II - o registro do pedido de \\ acesso em sistema \\ eletrônico específico e a \\ entrega de número do \\ protocolo, que conterá a \\ data de apresentação do \\ pedido; e \\ III - o encaminhamento do \\ pedido recebido $\mathrm{e}$ \\ registrado à unidade \\ responsável pelo \\ fornecimento da \\ informação, quando \\ couber. (DECRETO $\quad \mathrm{N}^{\mathrm{o}}$ \\ $7.724 / 2012)$
}

Quando se fala em transparência e disponibilização de informações aos interessados, a Lei de Acesso a Informação
I - informação - dados, processados ou não, que podem ser utilizados para produção e transmissão de conhecimento, contidos em qualquer meio, suporte ou formato;

II - dados processados dados submetidos a qualquer operação ou tratamento por meio de processamento eletrônico ou por meio automatizado com o emprego de tecnologia da informação;

III - documento - unidade de registro de informações, qualquer que seja o suporte ou formato;

IV - informação sigilosa informação submetida temporariamente à restrição de acesso público em razão de sua imprescindibilidade para a segurança da sociedade e do Estado, e aquelas abrangidas pelas demais hipóteses legais de sigilo;

V - informação pessoal informação relacionada à pessoa natural identificada ou identificável, relativa à intimidade, vida privada, honra e imagem;

VI - tratamento da informação - conjunto de ações referentes à produção, recepção, classificação, utilização, acesso, reprodução, transporte, transmissão, distribuição, arquivamento, armazenamento,

eliminação, avaliação, destinação ou controle da informação;

VII - disponibilidade qualidade da informação que pode ser conhecida e utilizada por indivíduos, equipamentos ou sistemas autorizados; 
VIII - autenticidade qualidade da informação que tenha sido produzida, expedida, recebida ou modificada por determinado indivíduo, equipamento ou sistema;

IX - integridade - qualidade da informação não modificada, inclusive quanto à origem, trânsito e destino;

$\mathrm{X}$ - primariedade qualidade da informação coletada na fonte, com o máximo de detalhamento possível, sem modificações; XI - informação atualizada - informação que reúne os dados mais recentes sobre o tema, de acordo com sua natureza, com os prazos previstos em normas específicas ou conforme a periodicidade estabelecida nos sistemas informatizados que a organizam; e

XII - documento preparatório - documento formal utilizado como fundamento da tomada de decisão ou de ato administrativo, a exemplo de pareceres e notas técnicas. (DECRETO No 7.724, 2012)

Sendo assim, de acordo com legislação tratada nesse artigo, qualquer pessoa pode requerer informações a respeito de qualquer órgão da administração pública, não sendo preciso apresentar nenhum tipo de justificativa para o pedido dessas informações. Portanto, podem ser solicitados quaisquer tipos de informações relacionadas às ações dos órgãos públicos, salvo as exceções legais. Através dessa garantia imposta pela lei, será possível, por exemplo, pedir informações do tipo quanto um ministério ou secretaria gastou com salários de servidores, com obras públicas, andamento de processos de licitação, detalhes sobre auditorias, fiscalizações e outras.

Caso o órgão não possa prestar as informações, deverá apresentar uma justificativa. Se o cidadão não acatar a justificativa, ele pode imediatamente entrar com recurso no próprio órgão onde solicitou as informações.

É importante ressaltar que não serão prestadas aos cidadãos informações consideradas sigilosas, tais como assuntos secretos do Estado, documentos que possam colocar em risco a segurança nacional ou que possam vir a comprometer alguma investigação policial. Informações de casos que corram em segredo de justiça também não poderão ser divulgadas, além de informações pessoais dos agentes públicos ou privados. Nesses casos, o órgão é obrigado a justificar ao requerente o motivo para não fornecer os dados.

As informações poderão ser solicitadas nos Serviços de Informações ao Cidadão (SICs), que os órgãos públicos deverão disponibilizar em estabelecimentos. A lei também determina que seja concedida ao cidadão a opção de solicitar os dados pela internet. A opção de outros meios como carta e telefone vai depender dos sistemas adotados por cada órgão. 
O cidadão poderá ainda obter as informações em um $\mathrm{CD}$ ou outra mídia digital. Se houver necessidade de impressão de um volume considerado elevado de papéis, o cidadão deverá pagar pelo custo do serviço.

Após o pedido das informações, se o órgão tiver a informação ao alcance imediato, o pedido poderá ser atendido no momento em que for feito pelo cidadão, nos SICs. Se houver necessidade de realizar pesquisa para atender à solicitação, demandando tempo, o órgão tem 20 dias, prorrogáveis por mais 10, para atender ao pedido. O cidadão deverá ser avisado por telefone ou pela internet. Passado esse prazo, o agente público tem que justificar o motivo da não prestação das informações solicitadas.

Os servidores das repartições públicas que não fornecerem as informações solicitadas e não apresentarem justificativa legal poderão sofrer sanções administrativas e até mesmo serem processados por improbidade.

\section{CONSIDERAÇÕES FINAIS}

O exercício da cidadania está diretamente ligado ao acesso à informação, uma vez que não conhecemos a maneira que a máquina pública está sendo gerenciada, será impossível praticar o controle social.
De fato, a Lei de Acesso à Informação Pública, somada aos demais mecanismos legais garantidores da publicidade, é um grande passo para a participação do cidadão no controle da gestação pública e para se exigir a devida transparência do Poder Público nas suas ações. Para isso, entendemos que muitos desafios precisam ser superados, afim de que a lei funcione efetivamente em prol do interesse da população e como instrumento inibidor da corrupção.

De acordo com a norma, qualquer cidadão tem o direito a obter informações nos órgãos públicos, além de ser orientado sobre como conseguir esse acesso, sem que seja necessário justificar-se. As repartições desses órgãos devem permitir pesquisa pela Internet e gravação dos dados em diversos formatos.

A mudança poderá, sem dúvida nenhuma, trazer vastos benefícios para o nosso país, garantindo uma relação mais saudável e transparente entre sociedade e governo, contribuindo assim como uma melhor fiscalização do serviço público resultando na redução da corrupção.

Devemos ter a consciência que o caminho ainda é longo a ser percorrido. O grande desafio a ser vencido é quebrar o receio das autoridades e dos servidores públicos em fornecer informação. É preciso que o Estado entenda que, por representar a população, deve ser por esta acessível quanto a seus atos. 
Sabemos que uma mudança de cultura de tal magnitude, em todos os níveis de governo, não se faz da noite para o dia, e a velocidade com que a lei será implantada é um verdadeiro desafio.

Os governos deverão investir na capacitação dos servidores para gerenciar novos sistemas de informação, atender ao cidadão e compreender a nova forma de tratar os dados públicos garantindo assim o cumprimento das normas.

A sociedade também terá um papel fundamental para que esses desafios sejam superados, pois deverão fazer o uso do seu direito a fim de promover resultados que sejam benéficos para a coletividade.

Devemos acreditar que com toda a legislação vigente em nosso país, que trata da obrigatoriedade dos gestores públicos darem transparência em seus atos de governo, estamos caminhando rumo a uma nova realidade, um serviço público de qualidade que atenda as necessidades da nossa população.

\section{BIBLIOGRAFIA}

\section{BICALHO, Lucídio. Transparência e}

Controle Social: a Lei Complementar

131/2009. Disponível em:<

http://blog.inesc.org.br/2009/06/25/transparen cia-e-controle-social-a-lei-complementar1312009/>. Acesso em: 12/11/2014.
BRASIL. Constituição da República Federativa do Brasil de 1988. Disponível em <http://www.planalto.gov.br/ccivil_03/constit uicao/constitui\%C3\%A7ao.htm>. Acesso em 30/07/2014.

.Decreto $\mathrm{n}^{\circ} 7.185$, de 27 de maio de 2010. Disponível em:

<http://www.planalto.gov.br/ccivil_03/_ato20

07-2010/2010/decreto/d7185.htm.>. Acesso

em 23/08/2014.

Decreto $\mathrm{n}^{\mathrm{o}} 7.724$, de 16 de maio de

2012. Disponível em:

<http://www.planalto.gov.br/ccivil_03/_ato201 1-2014/2012/Decreto/D7724.htm>. Acesso em $30 / 07 / 2014$.

Lei Complementar $n^{\circ} 101$, de 04 de maio de 2000. Disponível em:

$<$ http://www.tesouro.fazenda.gov.br/legislaca o/download/contabilidade/lei_comp_101_00. pdf >. Acesso em 30/07/2014.

. Lei Complementar $n^{\circ} 131$, de 27 de maio de 2009. Disponível em: <http://www.planalto.gov.br/ccivil_03/leis/lcp /lcp131.htm .>. Acesso em 30/07/2014.

.Lei $\mathrm{n}^{\circ} 12.527$, de 18 de novembro de 2011. Disponível em: <http://www.planalto.gov.br/ccivil_03/_ato20 11-2014/2011/lei/112527.htm > acesso em: 23/07/2014.

.Lei $\mathrm{N}^{\mathrm{o}} 4.320$, de 17 de março de 1964. Disponível em <http://www.planalto.gov.br/ccivil_03/leis/L4 320.htm . >. Acesso em 30/07/2014. 
DI PIETRO, M. S. Z. Direito

administrativo. 19.ed. 2.reimpr. São Paulo:

Atlas, 2006.

MEIRELES, H. L. Direito Administrativo

Brasileiro. 18.ed. São Paulo: RT, 1993.

Hely Lopes. Direito administrativo

brasileiro. 25. ed. São Paulo: Malheiros,

2000.

MELLO, Celso Antônio Bandeira de. Curso

de Direito Administrativo. 32. ed. São

Paulo: Malheiros, 2015.

NOGUEIRA, Carlos Alberto. Administração

Pública: Teoria e mais de 400 questões. $3^{\mathrm{a}}$.

Ed. Rio de Janeiro: Elsevier, 2006.

SILVA, Lino Martins da Silva.

Contabilidade Governamental. Um

Enfoque Administrativo. $5^{\text {a edição, São }}$

Paulo: Atlas, 2002. Pag 234

SLOMSKI, Valmor. Contabilidade pública:

um enfoque na contabilidade municipal. 2. ed.

São Paulo: Atlas, 2003. 